\title{
Un retrato de la mujer suburbial en el cine
}

\author{
María Asunción SALGAdo DE LA RosA \\ Departamento de Ideación Gráfica Arquitectónica \\ ETSAM / Universidad Politécnica de Madrid \\ mariaasuncion.salgado@upm.es
}

Recibido: $15 / 03 / 2013$

Modificado: $15 / 04 / 2013$

Aceptado: $11 / 05 / 2013$

\section{Resumen}

En las últimas décadas hemos visto cómo han proliferado en la periferia de nuestras ciudades grandes extensiones de asentamientos residenciales. Este modelo urbanístico se ha demostrado no sólo lesivo para el medio ambiente sino además ideológicamente erróneo. Concebido en EE.UU. como respuesta a la demanda de bienestar de una reciente clase media, su tipología fue penetrando paulatinamente en la ciudad europea a través del cine. Basada en premisas poco flexibles, pronto se revelaría como un modelo insatisfactorio para la mujer a la que en teoría iba dirigida.

Palabras clave: mujer, suburbio, ciudad, cine.

Title: A portrait of suburban women in cinema

Abstract

In recent decades we have experienced how large extensions of residential settlements have proliferated in the periphery of our cities. This urban model has been shown not only harmful to the environment but also ideologically wrong. Designed in the USA in response to the demand for welfare of an emerging middle class, their typology was gradually penetrating the European city through cinema. Based on inflexible assumptions, it was soon revealed as an unsatisfactory model for women to whom it was theoretically addressed.

Keywords: woman, suburb, city, cinema.

\section{Índice}

1. Introducción

2. El origen del cliché. La mujer y la máquina

3. Desmontando el modelo. Sacando a la mujer de su jaula suburbial 


\section{Introducción}

Es comúnmente aceptado que la ciudad es un espacio físico cambiante. Si bien la forma en la que se afrontan dichos cambios no es la única característica que las define, sí es una de las más importantes.

La mayoría de los cambios que afectan a los espacios urbanos sobrevienen a consecuencia de la inercia natural de las masas que los habitan, independientemente de las intenciones de políticos 0 urbanistas.

Desde hace un tiempo, los arquitectos lidiamos con el hecho de que cada ciudad tiene una idiosincrasia propia. Eso hace que el éxito o fracaso de cualquier intervención dependa, y mucho, de un concienzudo entendimiento de su diversidad. $Y$ por diversidad hay que entender todo, desde la religión, la raza, la educación o la economía, hasta por supuesto el género, siendo este último un factor que rara vez es considerado relevante.

Durante siglos la diversidad era una de las principales señas de identidad de los núcleos urbanos, especialmente en las zonas más consolidadas. La arquitectura de los centros de las ciudades absorbía los cambios demográficos con más solvencia que los nuevos asentamientos que aspiraban a formar parte de la ciudad.

Lamentablemente hemos sido testigos de cómo el modelo según el cual han crecido nuestras ciudades en los últimos tiempos ha sido erróneo. En general, se ha tratado de modelos que han pasado por alto cualquier tipo de estudio a la hora de promover los nuevos asentamientos que colonizan la periferia de los núcleos urbanos.

Todas las conclusiones extraídas tras siglos de desarrollo urbanístico parecen no haber sido tenidas en cuenta a la hora de planificar unos espacios concebidos para solventar una problemática concreta. Tomando como único factor de desarrollo la inversión económica, hemos permitido que se levantaran pequeños retazos de ciudad cuyas características "urbanas" son más que dudosas.

De hecho, llevamos décadas observando cómo proliferan en el extrarradio de muchas urbes europeas gigantescas colonias de viviendas cuyo crecimiento se basa en el sprawl ${ }^{1}$ un modelo de urbanismo dependiente del automóvil y claramente lesivo para el medio ambiente.

\footnotetext{
1 Se entiende como sprawl o urban sprawl a la expansión de zonas de baja densidad en el tejido suburbano. La temática relacionada con este concepto va desde los temas ambientales que tratan la relación con el medio ambiente de la periferia de una ciudad y sus alrededores, hasta sus límites lógicos, con el desarrollo de baja densidad y la dependencia del automóvil en suelo rústico, hasta conceptos ideológicos, políticos y sociológicos.
} 
Lo más triste no es tanto su proliferación en sí, sino su inoperancia consciente. Al mismo tiempo que se implantaban, se tenía el convencimiento de su escasa sostenibilidad frente al territorio. Sabiendo esto, ¿por qué se sigue repitiendo este modelo?

Muchas veces se ha esgrimido como argumento la existencia de una demanda creciente de este tipo de urbanizaciones, cuyo reclamo basado en la existencia de unas supuestas zonas verdes, pesaba más que las desventajas derivadas de su aislamiento. Teniendo en cuenta que se trataba de un modelo sin vinculación histórica con el esquema tradicional de ciudad mediterránea, es legítimo preguntarse de dónde ha surgido tal demanda.

Lo cierto es que, por sí solo, este modelo de ciudad apenas habría calado en Europa si no hubiera gozado de una gran campaña mediática. El éxito de este tipo de asentamiento se basa en la incorporación de un estereotipo que, por alguna razón, ha logrado penetrar profundamente en el ideario de la clase media. Estereotipo que, por otra parte, no se correspondía con los comportamientos sociales de las familias urbanas del sur de Europa y que, sin embargo, ha sido adoptado sin ser cuestionado. Un cliché al que según todas las estadísticas son más sensibles las mujeres y que, sin embargo, afecta en gran medida a la diversidad $y$, por lo tanto, al papel de la mujer en ese "nuevo" medio urbano.

La pregunta que nos surge respecto a este tema no es tanto el cómo sino de dónde surge la querencia por unos modelos de asentamiento cuya idoneidad ambiental, ideológica y moral resulta más que dudosa. La respuesta es que son herencia del urbanismo que proliferó en las ciudades americanas desde finales de la II Guerra Mundial, y la razón por la que han penetrado tan profundamente en el imaginario colectivo es porque su difusión ha ido de la mano del cine.

Siendo el cine la manifestación cultural más popular y Hollywood el paradigma de esta industria en occidente, se ha logrado la ilusión de que los modelos que el cine americano retrata son reflejos indirectos de la vida real. Un buen ejemplo de esto está en este tipo de asentamientos residenciales, cuya arquitectura vernácula y acrítica ha quedado como sinónimo de "hogar".

Revertir esta tendencia es harina de otro costal, pero el cambio puede conseguirse cambiando la imagen que el cine ofrece de la mujer contemporánea. El análisis de estos modelos urbanos aplicados a los personajes cinematográficos femeninos nos darán las pautas de su respectiva evolución. 


\section{El origen del cliché. La mujer y la máquina}

A principios de la década de los cincuenta, en EE.UU. gran parte de la población de clase media vio cumplido el ideal de independencia ligado al sueño americano mediante la adquisición de una vivienda unifamiliar. La concesión de garantías hipotecarias a los veteranos de guerra tras la II Guerra Mundial y una política de construcción de nuevas viviendas que habían de hacer frente a la escasez de las mismas, hizo posible que para los años sesenta la bolsa de población en suburbios fuera equiparable a la de las ciudades. El tipo de urbanismo resultante y las infraestructuras planeadas hicieron del aislamiento un ideal que envolvía al suburbio. Este aislamiento alcanzará de forma desigual a los distintos miembros de la familia, suponiendo un importante escollo para el ama de casa. La vida de ésta quedó reducida al dominio de una estancia -la cocina-, que en compensación fue llenándose de robots. Su incomunicación se fue haciendo mayor a medida que las tareas del hogar se mecanizaban, dejándole más tiempo para pensar.

Este desplazamiento de las zonas residenciales de clase media a las afueras de las ciudades venía acompañado no sólo de un programa espacial conveniente para cada estructura familiar, sino también de todos aquellos avances tecnológicos que simbolizaban ese nuevo estilo de vida. Mientras el aspecto interior de la vivienda se adaptaba a los avances tecnológicos, estos retazos de ciudad se convertían en aberraciones demográficas habitadas mayoritariamente por mujeres durante el día y casi desiertas por la noche.

Este tipo de urbanización dispersa en la que prima el vehículo privado en detrimento del transporte colectivo, tuvo en la pareja de arquitectos Charles y Ray Eames a sus principales propagandistas. Sin embargo, tras este ideal arquitectónico se escondía un sentimiento de insatisfacción que generó un proceso de enajenación del habitante suburbano, capaz de convertirlo en un comprador compulsivo y, por lo tanto, un inconsciente consumidor de bienes mecánicos. A mediados de los 50, la desenfrenada carrera armamentística y el comienzo de lo que sería la carrera espacial hacían que la pasión por la robótica salpicara cualquier aspecto de la vida cotidiana.

En 1954 en Inglaterra, el sociólogo Lawrence Alloway y el artista McHale discutían en el seno del Independent Group ${ }^{2}$ con el

2 The Independent Group, fundado en 1952, constituyó un foro de discusión que surgió en el seno del Institute of Contemporary Arts (ICA) en Londres. Entre sus miembros se incluían los artistas Eduardo Paolozzi, Richard Hamilton, William Turnbull y John McHale, el crítico Lawrence Alloway, y los arquitectos Alison y Peter Smithson. El grupo fue vital para el desarrollo de Pop en el Reino Unido. Se interesaron por la ciencia-ficción, las revistas americanas, los diseños de 
historiador Banham sobre todo lo que rodeaba a la cultura popular y su relación con la arquitectura. Dos años después, tras un viaje a EE.UU., McHale vuelve a Inglaterra con un baúl lleno de revistas y anuncios americanos que vendían toda clase de electrodomésticos y pequeños aparatos al ama de casa americana. Sus colegas del Independent Group, tras hacer una selección, dejaron que estos sirvieran de base para el collage de Hamilton Just What is it That Makes Today's Homes so Appealing? (figura 2), que mostraba una casa decorada a partir de los deseos consumistas de sus habitantes.

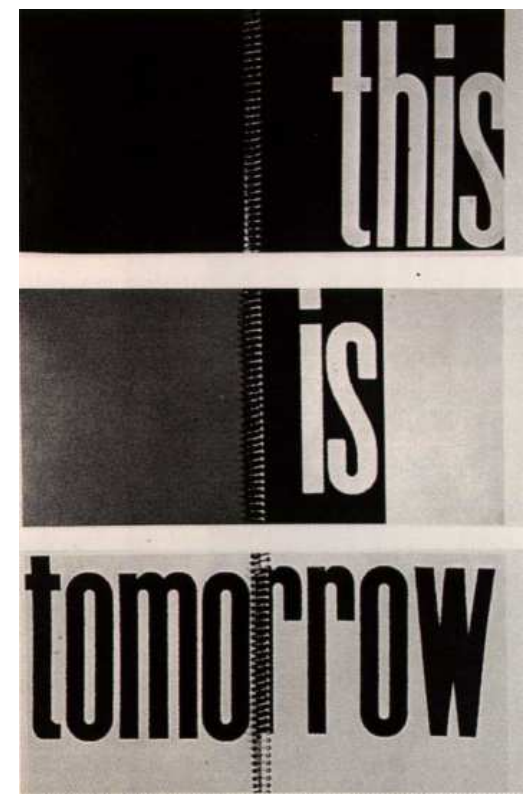

Figura 1. Cartel y collage de Hamilton para la exposición This is Tomorrow en el ICA.

Figura 2. Collage de Hamilton "Just What is it That Makes Today's Homes so Appealing?

En 1958, Alloway, en un ensayo para la revista Architectural Design (Alloway 1958: 34), lanzaba por primera vez el término Pop, a la vez que McHale yuxtaponía imágenes de las casas de Frey o de Fuller con las novedades en electrodomésticos. Esto sucedía tan sólo un año después de que en Francia Guy Debord publicara La sociedad del espectáculo (Debord 1967: 1), diagnosticando con gran lucidez lo que más adelante vendría: la transformación de la vida doméstica como consecuencia de su relación con los medios de comunicación.

Mientras que en EE.UU. se ponía en cuestión la arquitectura moderna desde una visión puramente estética, en Europa surgían diversas voces críticas que alertaban sobre las consecuencias del nuevo modelo urbanístico.

automóviles, el folclore, la publicidad, etc., y legitimó ese material como materia de investigación cultural seria. 
Conviene aclarar que en EE.UU. la implantación de la vivienda moderna en el seno de la clase media nunca tuvo ningún éxito. De hecho, el rechazo de la condición aparentemente abstracta y carente de humanidad de la arquitectura moderna encontró voz en el matrimonio Venturi.

Fruto de esas corrientes ideológicas acompañadas de un incesante movimiento de proliferación de viviendas unifamiliares en las afueras de las ciudades, surgieron auténticos asentamientos urbanos totalmente nuevos, compuestos únicamente de viviendas al amparo de un gran centro comercial, que respondían al ideal de "pequeña población americana de casitas de madera y cercas blancas". Con ellas, los arquitectos lograban satisfacer una demanda real a la vez que se convertirían en símbolos de un nuevo urbanismo norteamericano, cosa que a juicio del crítico Herbert Muschamp (Fernández Galiano 2000: 21), no suponía más que el camuflaje de una sociedad que desde 1945 se había basado en el consumo.

Claramente estos modelos de ciudad importados de EE.UU. venían asociados a una imagen concreta de sociedad y, más concretamente, de la mujer con la que la intelectualidad europea no estaba del todo de acuerdo.

Mientras el cine americano publicitaba el modelo sin el más mínimo atisbo de autocrítica, en Europa Jaques Tati se anticipa en un año a la irrupción de la Nouvelle Vague. En 1958 rueda Mon Oncle (Mi tío), película en la que toma la vivienda como tema central, en consonancia con la preocupación de los tiempos de posguerra.

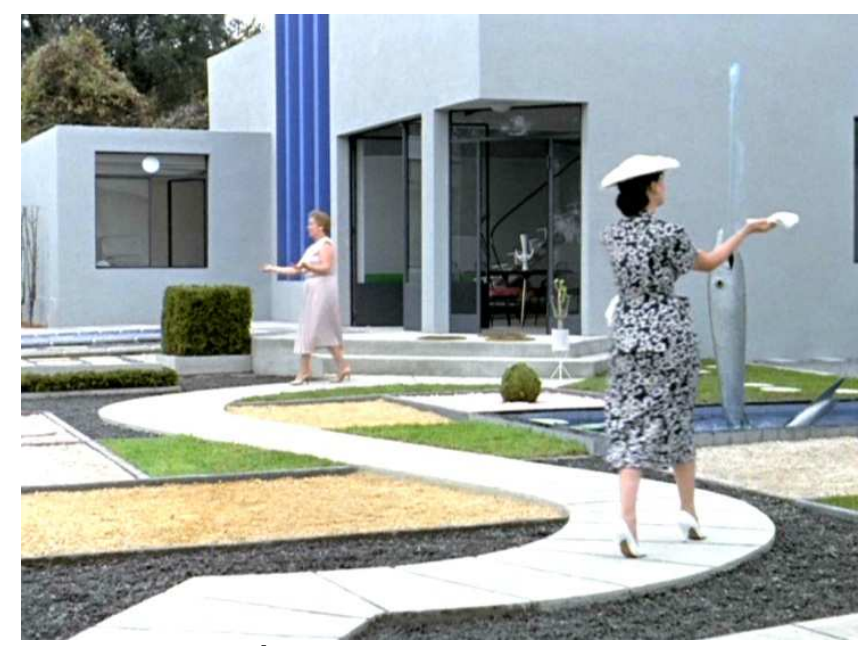

Figura 3. Escena extraída de Mon Oncle (1958) de Jacques Tati.

Tati ya había criticado y servido de cronista de la ciudad moderna. Usó el cristal como último símbolo del modernismo capaz de generar ambigüedad espacial. Alertaba sobre el bloque de las oficinas y los rascacielos - preocupaciones que se convirtieron en el tema central de los sesenta-, a la vez que ponía de manifiesto la 
insulsa uniformidad de la Ciudad Jardín de los cincuenta. Por esa razón la vivienda de los Arpel se sitúa en uno de esos barrios ajardinados de la periferia de París, aunque con matices.

Mientras que el rol de la mujer americana en relación con los nuevos asentamientos se plantea como epicentro de la familia y poseedora de una suerte de moralidad, el rol de la mujer europea es más cómico y poliédrico.

En el caso de Mon Oncle, los cambios paulatinos experimentados por la sociedad urbana son reflejados por Tati coincidiendo con la revisión de la ciudad moderna, cuya representación se extiende tanto al cine como a la arquitectura. Tati alerta en sus filmes de la tiranía que produce la mecanización ligada a la arquitectura moderna, pero su discurso "postmoderno", al igual que en el de Venturi, no muestra un rechazo total a dicha arquitectura, sino una postura de experiencia crítica en la que se reivindica una añorada sobrecarga visual a través del collage de imágenes.

La relación de Madame Arpel con su arquitectura no resulta ni tan asfixiante ni tan ñoña como en las películas americanas de la época, a pesar de que representa el mismo modelo de mujer casada y ama de casa de mediana edad.

Y ahí está la clave. Mientras que en Hollywood el rol de la mujer urbana retratado por el cine negro de los años treinta fue dando paso a un modelo monocorde asociado a la uniformidad ambiental y familiar, en Europa el testigo de estas mujeres interesantes y complejas surge de la mano de la Nouvelle Vague.

En el viejo continente, a raíz de las transformaciones que experimentó el tejido urbano en relación con el cambio en el modo de vida de sus habitantes, surgirían las utopías desencadenadas por las derivas situacionistas.

Coincidiendo con una operación de renovación y sustitución del tejido social de la ciudad, la cultura de consumo de posguerra se hacía visible a finales de los cincuenta en la ciudad de París, al proliferar la modernización de muchas de las fachadas destinadas a pequeños negocios. Bajo las órdenes del entonces Ministro de Construcción, los franceses observaron cómo las construcciones masivas de vivienda obrera en barrios periféricos o new towns acababan con las bolsas de subdesarrollo que constituían los focos de contradicción urbana. Con esta operación el gobierno garantizaba además la dispersión de gran parte de este estrato social.

Durante la década de los 60, la visión crítica de Guy Debord asociaría estos cambios a "las consecuencias espaciales de la producción capitalista" (Debord 1988: 23). 


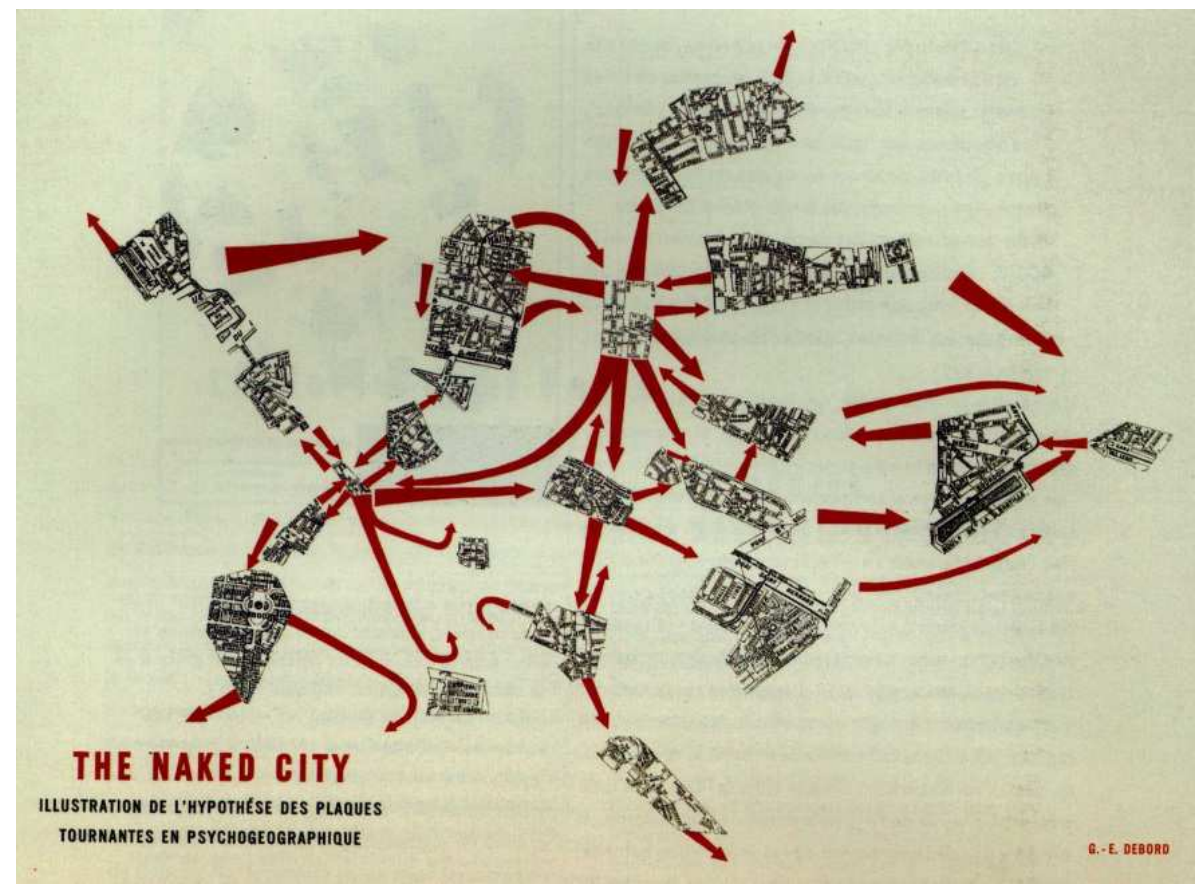

Figura 4. Guy Debord, The Naked City (1957).

Empezaba a vivirse el auge de la televisión en los hogares. La relación ambivalente de este electrodoméstico en las zonas residenciales fue criticado desde aquellos sectores más intelectuales que alertaban de la tiranía del poder a través de los medios. Es el caso de las versiones cinematográficas de Farenheit 451 (Truffaut, dir., 1966) o la posterior 1984 (Radford, dir., 1984), que ponían de manifiesto ese clima alienante que se le presumía al modelo.

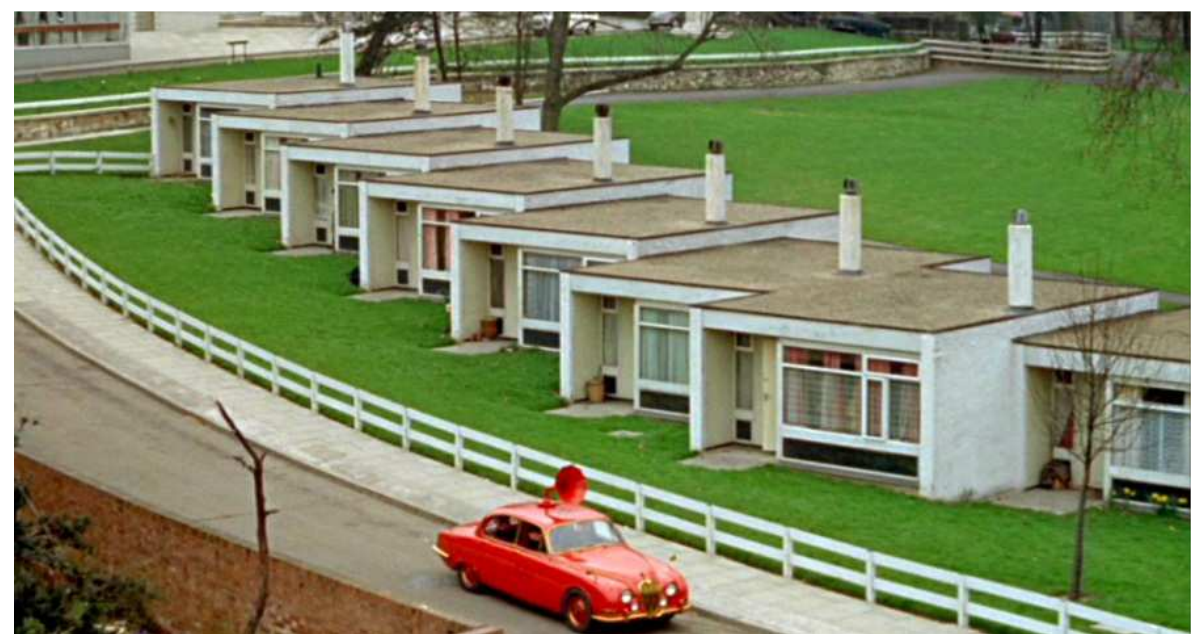

Figura 5. Aproximación a la casa del protagonista. Escena extraída de la película Farenheit 451, de Truffaut (1966). 


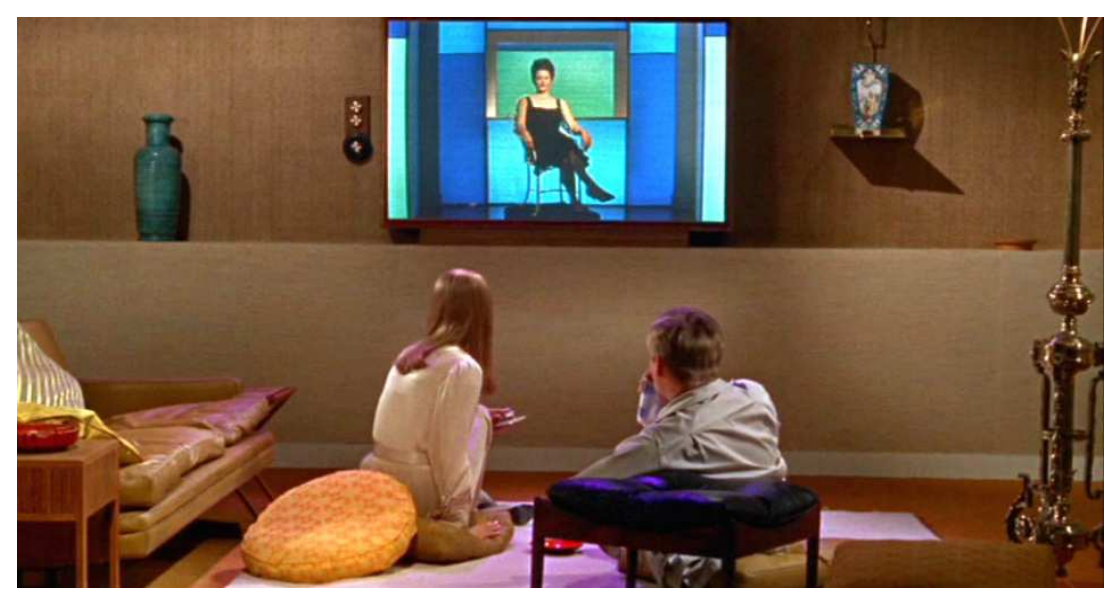

Figura 6. Interior de la casa del protagonista. Escena extraída de la película Farenheit 451, de Truffaut (1966).

Según Debord, la evolución de esta sociedad modernizada hasta alcanzar el estadio de "espectacular integrado", responde al efecto combinado de cinco rasgos principales: la innovación tecnológica, inherente a la sociedad capitalista pero acelerada a partir del final de la Segunda Guerra Mundial de forma incesante; la fusión de la economía y el estado; el secreto generalizado; la falsedad sin respuesta, y un presente perpetuo (Debord 1988: 23). De esta manera, Debord establece las pautas de la contradicción que se plantea en toda sociedad espectacular al tratar de avanzar sobreviviendo a la resaca tecnológica y sin necesidad de prescindir de ella.

Al calor de este ambiente contradictorio comenzaron a producirse muchos cambios sociales que afectaban a las minorías y al papel de la mujer. Al mismo tiempo que se consolidaba la demanda por los derechos civiles de la población negra, empezó el despertar de la conciencia femenina que reclamaba un lugar en la sociedad. Estos cambios poco a poco se verían reflejados en la televisión, llegando con más tardanza al cine.

Con la crisis del petróleo de principios de los setenta, el sentimiento de positivismo y de fascinación que producían la carrera espacial y las novedades tecnológicas había sido puesto en duda por una sociedad que asistía asombrada al nacimiento de los procesadores de datos a nivel doméstico. Numerosos movimientos cuestionaban ya desde finales de los sesenta la utopía de que el progreso indefinido conducía a la felicidad, a la vez que crecía entre la gente el sentimiento catastrófico al que nos llevaría una imparable carrera armamentística.

Entramos en una nueva era en la que los avances tecnológicos que afectan a los aspectos del hogar del individuo son mostrados a través de películas de ciencia-ficción con altos grados de pesimismo, como El planeta de los simios (Schaffner, dir., 1968) o Cuando el destino nos alcance (Fleischer, dir., 1973), películas en las que la 
sofisticación tecnológica era similar a la de las cintas de décadas anteriores y que, sin embargo, marcaron el sentir de toda una época. El gusto por la introducción de la mecanización en el cine, como parte de un atrezo que sorprende al espectador, pasa a un segundo plano frente a la desesperanza que imprime el peso argumental. Por esa época Kubrick maravilló al mundo con 2001: Una odisea en el espacio (Kubrick, dir., 1968), introduciendo no solo toda una gama de nuevos materiales y tecnologías integradas en un ámbito habitable, sino que dio verosimilitud al anhelo de escapar de este planeta.

Junto a los nuevos escenarios surgían movimientos que fomentaban el cambio de rol de la mujer en el cine americano. Los primeros ejemplos aparecieron de la mano del cine de ciencia-ficción, donde se proponían nuevos roles que cambiarían el comportamiento sumiso de la mujer de posguerra. La teniente Ripley de Alien (Scott, dir., 1979) fue la primera de toda una serie de heroínas cinematográficas de Hollywood, una tendencia que continuaría hasta nuestros días. Al mismo tiempo, desde una perspectiva más intimista, Woody Allen se desmarcaría de la línea de Hollywood retratando un tipo de mujer urbana muy concreta: la neoyorkina.

Pronto surgirán a ambos lados del océano movimientos feministas que vendrían a poner en cuestión ciertos valores asociados a un modelo que trataba de imponer un pensamiento único para esta nueva sociedad de consumo. En lo que al cine re refiere, el cambio de escenografía urbana asociado a esta nueva mujer habría de esperar hasta el fin del milenio.

\section{Desmontando el modelo. Sacando a la mujer de su jaula suburbial}

Mientras los géneros fantásticos y de acción se ajustaban a los cambios de rol femeninos, desde la comedia o el drama se seguía dando publicidad al crecimiento de los asentamientos suburbanos como escenarios del clásico final feliz. Esta adjetivación de este tipo de localizaciones se conseguía por asociación, identificando la culminación del amor romántico con el matrimonio, los hijos, el perro y la casa en las afueras.

En el cine de autor, por el contrario, los escenarios sentimentales no precisan de una deserción de la ciudad.

Hicieron falta varias décadas para que desde el cine surgieran voces críticas relativas al formato de la ciudad suburbial. Curiosamente estas voces surgieron desde Hollywood, pero de la mano de directores no americanos. Muchas de estas cintas se presentan en clave revisionista de hechos pretéritos.

Películas como American Beauty de Sam Mendes (1999) o Pleasantville de Gary Ross (1998) utilizan el humor para criticar todo un modelo social a través del retrato de su escenario urbano. El aspecto más dramático de ambas estriba en el daño que produce la 
uniformidad en la vida de sus habitantes. Una uniformidad que al contrario de las propuestas más catastrofistas del tipo Fahrenheit 451 o 1984, que hablaban de sociedades opresoras basadas en relatos de ficción, se ambienta en un entorno real -en este caso el suburbioque fue construido con vocación de prosperidad e independencia y que, sin embargo, se ha revelado como asfixiante.

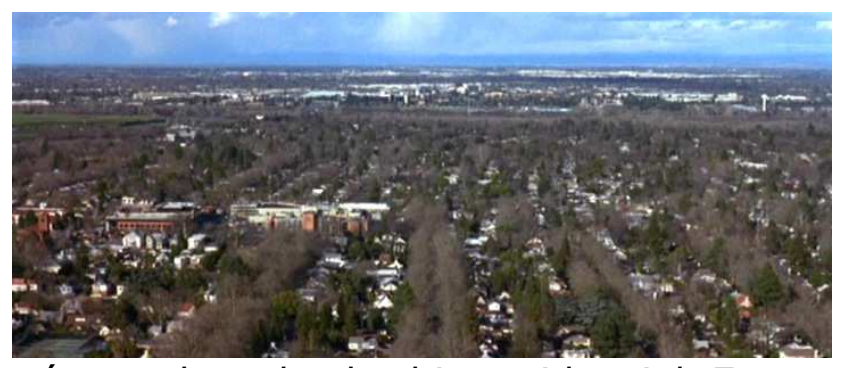

Figura 7. Vista aérea sobre el suburbio residencial. Escena extraída de la película American Beauty, de Sam Mendes (1999).

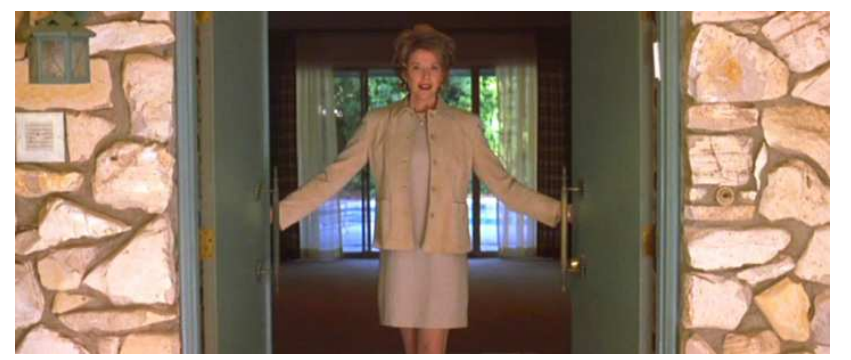

Figura 8. Protagonista abriendo la puerta de la vivienda. Escena extraída de la película American Beauty, de Sam Mendes (1999).

Esta insatisfacción provocada por el escenario suburbial es percibida con mayor intensidad por las mujeres, cuya aspiración de una vida mejor las redujo a meras consumidoras, es decir, a proveedoras de bienes para su hogar. Este tipo de asentamientos prometían un hogar singular, que aportaba privacidad y en el que primaban ciertos valores ambientales. La realidad ha revelado que se trata de asentamientos manifiestamente uniformes, que aíslan a sus habitantes y que son lesivos para el medio ambiente.

A pesar de ello, existen escasos ejemplos de alternativas desde el punto de vista urbanístico. Un ejemplo de esto nos lo muestra el australiano Peter Weir al utilizar como escenario el pueblo de Seaside. En 1998 este director filma el Show de Truman. Por encima de la lectura acerca de los límites del poder mediático de la televisión, esta película nos habla del engaño que encierra la homogeneidad urbana.

La desconfianza manifestada por muchos americanos en la década de los cincuenta frente a la uniformidad que supuestamente subyacía bajo aquellas arquitecturas fieles al Estilo Internacional, y que llegaron incluso a ser comparadas con el totalitarismo de la propaganda comunista, fue dando paso a grandes asentamientos de 
viviendas de clase media plagados de construcciones ajenas a cualquier representación de lo moderno al amparo de la herencia de unos esquemas tradicionales mal entendidos. La parcelación uniforme de viviendas unifamiliares y la escasa distinción entre calles y avenidas, operaba una uniformidad del medio que despojaba al sujeto de su individualidad, haciéndolo formar parte de un colectivo.

El modo de vida ordinario que promovía el crecimiento en mancha de aceite, tan publicitado en otro tiempo a través del cine, lleva soportando varios años de crítica a sus espaldas, que lo acusan de ser el causante, entre otras cosas, del deterioro de un medio natural con el que se sentía involucrado. Sin embargo, la arquitectura surgida como consecuencia de dicho estilo de vida y ese "urbanismo de consumo de masas", no fue cuestionado hasta bien entrada la década de los noventa, cuando el cine transformó la comedia familiar asentada en el suburbio en ácidas críticas tragicómicas en las que los vicios más inconfesables podían esconderse tras las puertas de una de esas "casitas de madera".

La denuncia vertida acerca de la vulgaridad de aquellos que viven en un entorno carente de hitos significativos, ha sido caricaturizada con brillantez en los últimos años en películas como Eduardo Manostijeras (1990) de Tim Burton, Pleasantville (1998) de Gary Ross, American Beauty (1999) de Sam Mendes o la propia El Show de Truman.

La urbanización coloreada que Burton caricaturiza en tono de fábula de dimensiones mágicas, o la que Mendes describe como un lugar de apariencia inofensiva en el que se esconden los peores impulsos del ser humano, alcanza en la cinta de Weir el apelativo de "maliciosa artificialidad", al lograr retratar toda una ciudad en el papel de un gigantesco decorado.

Rodada íntegramente en Florida, la isla en la que vive Truman, Seaheven, es en realidad Seaside, pueblo surgido al amparo de las teorías del nuevo urbanismo, propuesta por los arquitectos Andrés Duany y Elisabeth Plater-Zyberk.

Este pueblo de Florida en el que, según sus autores, se pretendió recuperar los principios urbanísticos decimonónicos como antídoto frente al sprawl, reunía las condiciones precisas que lo hacían parecer tan artificial como un decorado. Calles interconectadas con escasez de vías rápidas que reducen el tráfico, viviendas alineadas que ofrecen una línea de fachada homogénea a la vía, líneas de arbolado paralelas, limitación del número de plazas de aparcamiento urbanas, y servicios localizados a tan sólo 5 minutos de cualquier punto sirven de base a una comunidad residencial en la que se pretende aportar un hogar de idéntica estructura "para todo el mundo", independientemente de su condición social o económica. 


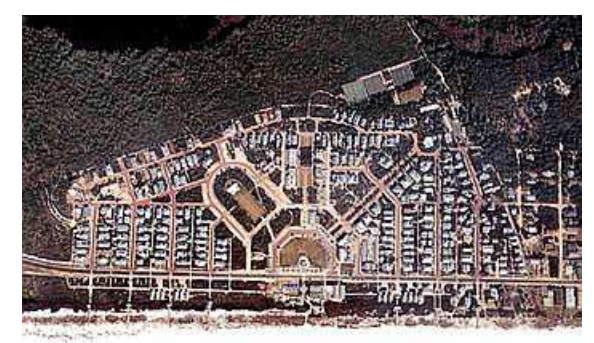

Figura 9. Vista aérea del planeamiento de Seaside.

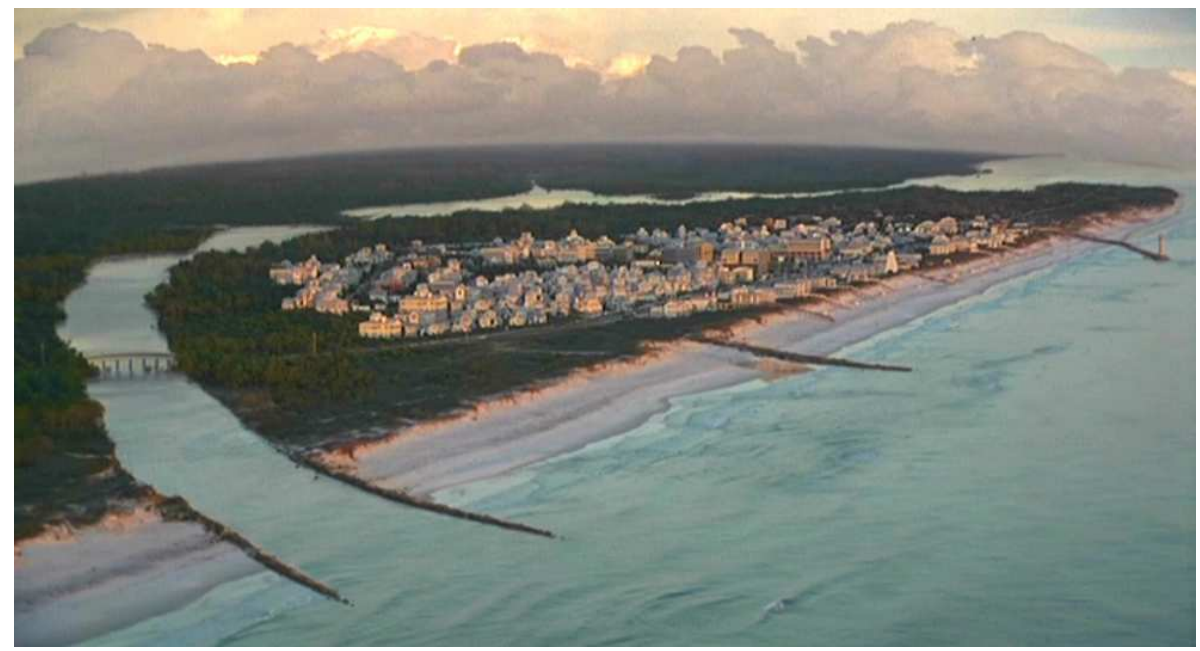

Figura 10. Imagen de Seaside extraída de la película El Show de Truman, del director australiano Peter Weir (1998).

El origen de Seaside se remonta a 1979 cuando su promotor, Robert S. Davis, heredó los cerca de 100 acres de terreno situados en una isla frente al océano. No queriendo crear otra comunidad dependiente del automóvil, Davis y su mujer contactaron con la pareja de urbanistas Duany y Plater-Zyberk para analizar las condiciones que más interesaban al ciudadano a la hora de asentarse en un territorio. El resultado fue este pueblo que se construyó en tan solo tres años.

Al margen de una estructura más o menos conveniente con servicios que fomentan el uso del transporte público, la ausencia de variedad de estilos, formas y materiales en su arquitectura, otorga a dicho asentamiento un aspecto sospechosamente artificial a través de lo que para algunos podría ser interpretado como belleza armónica y cuyas variaciones resultan, cuando menos, inquietantes. 


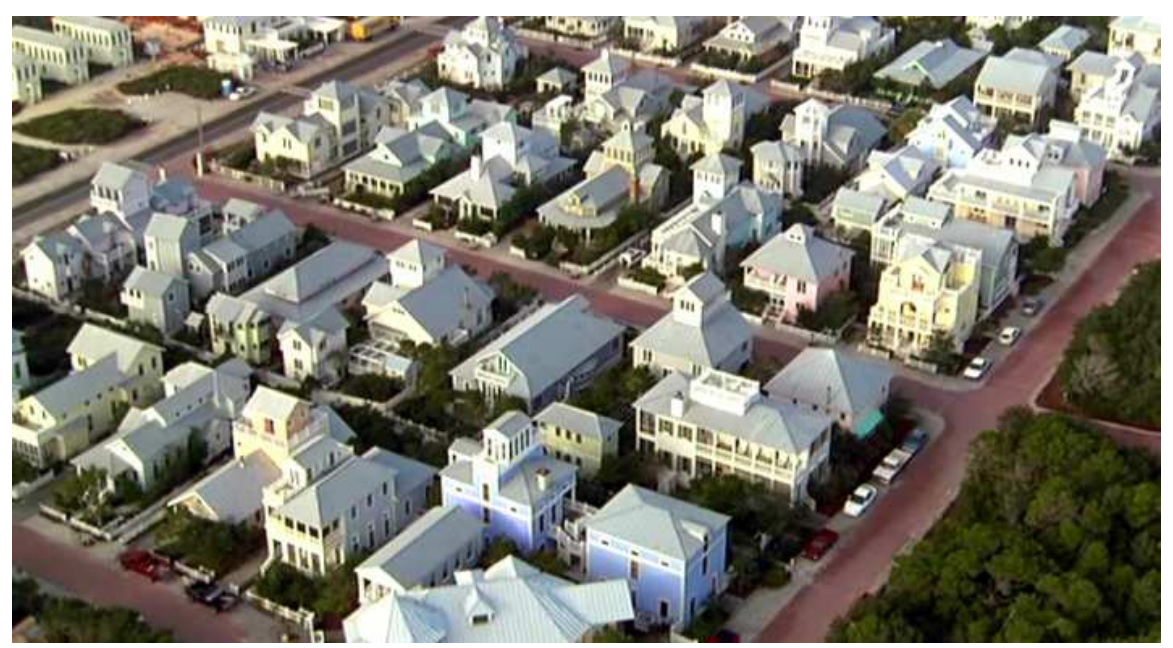

Figura 11. Vista aérea de Seaside extraída de la película El Show de Truman, del director australiano Peter Weir (1998).

En la isla de Seaheven, no existe objeto de comparación. A toda costa, el protagonista desea escapar de una vida en la que todo es aburrida felicidad y siniestra belleza, en la que la gente que le rodea desprende un sospechoso tufillo a anuncio publicitario. En clave de tragicomedia, el Show de Truman no sólo vende productos por televisión, también vende un estilo de vida.

Seaside podría constituir un buen ejemplo de revisión del modelo de asentamiento residencial de nueva planta, por lo menos en lo que a implantación en el territorio se refiere. Sin embargo, a pesar de su programa, este modelo no acaba de funcionar satisfactoriamente más allá del modelo vacacional para la tercera edad al que finalmente se destinó. Esto es así porque de base niega la diversidad.

La ficción nos ha mostrado lo alienante que puede llegar a ser un entorno uniforme, independientemente de cuál sea su naturaleza. Tan contundentes como los relatos cinematográficos de las ficciones de Orwell o Bradbury son los retratos que Ang Lee o el propio Sam Mendes hicieron respectivamente a través de las cintas La tormenta de hielo (Lee, dir., 1997) o Revolutionary Road (Mendes, dir., 2008).

En ambas, el retrato de la familia suburbial es demoledor. Estos retratos, narrados desde la perspectiva de sus protagonistas femeninos, se hacen extensibles a su escenografía, transformando para siempre el estereotipo de almibarada felicidad con el que se publicitaba el "american way of life".

Del mismo modo que el cine americano contribuyó a difundir este modelo urbano como una parte inherente a su cultura e ideales, el cine puede ayudar a su transformación.

Parte del conflicto que se ha generado con estos asentamientos radica en su concepción de base. Bajo la premisa de crear entornos "adecuados" para la crianza de los hijos, se subestimó la capacidad 
de la mujer para desempeñar cualquier labor fuera del ámbito familiar. Estos entornos biempensantes se convirtieron en involuntarias jaulas en las que la diversidad no tenía cabida.

Estas decisiones de planeamiento creadas sobre papel resultaron tremendamente paternalistas con las mujeres una vez fueron llevadas a cabo. Además adolecían ya de base de las mismas carencias que surgen en los guetos que crecen de forma espontánea en la periferia urbana. La diferencia entre ambos radica en el deseo consciente del primero, frente a las imposiciones dictadas por la realidad social del segundo. Un deseo proveniente de las propias mujeres que han dado por bueno el mensaje mediático de que este urbanismo es el adecuado, cuando en realidad no lo es.

Al final el problema de ambos casos es el mismo: económico, siendo el primero más lesivo al ser más difícil de absorber por el tejido urbano. En definitiva, más allá de una apuesta, estos grandes asentamientos residenciales en extensión constituyen una estafa consciente de la que todos hemos sido partícipes en distinto grado.

La diferencia es que hoy ya no podemos declararnos ignorantes de sus consecuencias y nuestra obligación es aprender de los errores. Desconfiemos de las propuestas que tratan de facilitar a un género, a una raza o a un grupo de edad en detrimento de la diversidad. La ciudad que funciona es aquella que no se ajusta a un modelo, sino que permite que quepan todos.

Es hora de rechazar el cliché.

\section{Bibliografía}

ALLOWAY, Lawrence (1958): "The Arts and the Mass Media". Architectural Design, February 1958, p. 34.

CASTILLO, Greg (2010): Cold War on the Home Front. The Soft Power of Midcentury Design. Minneapolis: University of Minnesota Press.

DEBORD, Guy (1967): La société du spectacle. París: Champ Libre.

DEBORD, Guy (1988): Comentarios sobre la sociedad del espectáculo. París: Anagrama.

FERNÁNDEZ GALIANO, Luis (2000): "Belleza Americana". Babelia, El País, $15 / 04 / 2000$, p. 21.

GOROSTIZA, J. et al. (2007): Paradigmas. El desarrollo de la modernidad arquitectónica visto a través de la historia del cine. Madrid: Fundación Telefónica.

RAMÍREZ, J. A. (1993): La arquitectura en el cine. Hollywood, la Edad de Oro. Madrid: Alianza. 


\section{Filmografía}

BURTON, Tim (dir.) (1990): Eduardo Manostijeras (Edward Scissorhands). EE.UU.: Twentieth Century Fox Film Corporation.

FLEISCHER, Richard (dir.) (1973): Cuando el destino nos alcance (Soylent Green). EE.UU.: Metro-Goldwyn-Mayer (MGM).

KUBRICK, Stanley (dir.) (1968): 2001: Una odisea en el espacio (2001: A Space Odyssey). EE.UU.: Metro-Goldwyn-Mayer (MGM).

LEE, Ang (dir.) (1997): La tormenta de hielo (The Ice Storm). EE.UU.: Fox Searchlight Pictures.

MENDES, Sam (dir.) (1999): American Beauty. EE.UU.: Dream Works SKG.

MENDES, Sam (dir.) (2008): Revolutionary Road. EE.UU.: Dream Works SKG.

RADFORD, Michael (dir.) (1984): 1984 (Nineteen Eighty-Four). EE.UU.: Umbrella-Rosenblum Films Production.

ROSS, Gary (dir.) (1998): Pleasantville. EE.UU.: New Line Cinema.

SCHAFFNER, Franklin J. (dir.) (1968): El planeta de los simios (Planet of the Apes). EE.UU.: Twentieth Century Fox Film Corporation.

SCOTT, Ridley (dir.) (1979): Alien. EE.UU.: Twentieth Century-Fox Productions.

TATI, Jacques (dir.) (1958): Mi tío (Mon Oncle). Francia: Les Films de Mon Oncle.

TRUFFAUT, Françoise (dir.) (1966): Farenheit 451. Francia: Vineyard Film Ltd.

WEIR, Peter (dir.) (1998): El show de Truman (The Truman Show). EE.UU.: Paramount Pictures. 